\title{
Protein disulfide isomerase A1 regulates breast cancer cell immunorecognition in a manner dependent on redox state
}

\author{
RASHED ALHAMMAD ${ }^{1}$, SASIPRAPA KHUNCHAI ${ }^{2}$, NOPPRARAT TONGMUANG ${ }^{3}$, \\ THAWORNCHAI LIMJINDAPORN ${ }^{3,4}$, PA-THAI YENCHITSOMANUS ${ }^{3,5}$, LUCIANO MUTTI ${ }^{6,7}$, \\ MARIJA KRSTIC-DEMONACOS ${ }^{8}$ and CONSTANTINOS DEMONACOS ${ }^{1}$
}

\begin{abstract}
${ }^{1}$ Faculty of Biology Medicine and Health, School of Health Sciences, Division of Pharmacy and Optometry, University of Manchester, Manchester M13 9PT, UK; ${ }^{2}$ Department of Anatomy, Faculty of Medical Science, Naresuan University, Phitsanulok 65000; ${ }^{3}$ Division of Molecular Medicine, Research Department, Faculty of Medicine Siriraj Hospital, Mahidol University; ${ }^{4}$ Department of Anatomy, Faculty of Medicine Siriraj Hospital, Mahidol University; ${ }^{5}$ Siriraj Center of Research Excellence for Cancer Immunotherapy (SiCORE-CIT), Faculty of Medicine Siriraj Hospital, Mahidol University, Bangkok 10700, Thailand; ${ }^{6}$ Sbarro Institute for Cancer Research and Molecular Medicine, Center for Biotechnology, College of Science and Technology, Temple University, Philadelphia, PA 19122, USA; ${ }^{7} \mathrm{GIMe}$, Italian Mesothelioma Group, I-15033 Casale Monferrato, Italy; ${ }^{8}$ University of Salford, School of Science, Engineering and Environment, Salford M5 4WT, UK
\end{abstract}

Received May 29, 2020; Accepted September 1, 2020

DOI: $10.3892 /$ or.2020.7816

\begin{abstract}
Oxidoreductase protein disulphide isomerases (PDI) are involved in the regulation of a variety of biological processes including the modulation of endoplasmic reticulum (ER) stress, unfolded protein response (UPR), ER-mitochondria communication and the balance between pro-survival and pro-death pathways. In the current study the role of the PDIA1 family member in breast carcinogenesis was investigated by measuring ROS generation, mitochondrial membrane disruption, ATP production and HLA-G protein levels on the surface of the cellular membrane in the presence or absence of PDIA1. The results showed that this enzyme exerted pro-apoptotic effects in estrogen receptor (ER $\alpha$ )-positive breast cancer MCF-7 and pro-survival in triple negative breast cancer (TNBC) MDA-MB-231 cells. ATP
\end{abstract}

Correspondence to: Dr Constantinos Demonacos, Faculty of Biology Medicine and Health, School of Health Sciences, Division of Pharmacy and Optometry, University of Manchester, Oxford Road, Manchester M13 9PT, UK

E-mail: constantinos.demonacos@manchester.ac.uk

Abbreviations: PDI, protein disulphide isomerase; ROS, reactive oxygen species; TNBC, triple negative breast cancer; MMD, mitochondrial membrane disruption; RISC, RNA-interfering silencing complex

Key words: protein disulfide isomerase, reactive oxygen species, endoplasmic reticulum stress, transcription, antigen presentation, breast cancer generation was upregulated in PDIAl-silenced MCF-7 cells and downregulated in PDIA1-silenced MDA-MB-231 cells in a manner dependent on the cellular redox status. Furthermore, MCF-7 and MDA-MB-231 cells in the presence of PDIA1 expressed higher surface levels of the non-classical human leukocyte antigen (HLA-G) under oxidative stress conditions. Evaluation of the METABRIC datasets showed that low PDIAI and high $H L A-G$ mRNA expression levels correlated with longer survival in both ER $\alpha$-positive and ER $\alpha$-negative stage 2 breast cancer patients. In addition, analysis of the PDIAI vs. the $H L A-G$ mRNA ratio in the subgroup of the living stage 2 breast cancer patients exhibiting low PDIA1 and high HLA-G mRNA levels revealed that the longer the survival time of the ratio was high PDIAI and low HLA-G mRNA and occurred predominantly in ER $\alpha$-positive breast cancer patients whereas in the same subgroup of the ER $\alpha$-negative breast cancer mainly this ratio was low PDIAl and high HLA-G mRNA. Taken together these results provide evidence supporting the view that PDIA1 is linked to several hallmarks of breast cancer pathways including the process of antigen processing and presentation and tumor immunorecognition.

\section{Introduction}

The fine-tuning of the intracellular levels of reactive oxygen species (ROS) and the cellular redox state is of crucial importance for breast carcinogenesis, progression, prognosis and therapy (1). ROS are involved in multiple redox regulated signaling pathways including the modulation of endoplasmic reticulum and mitochondria homeostasis and contribute to the pathogenesis of a number of human diseases including breast cancer (2). Cancer cells generate persistently high ROS levels which activate pro-survival mechanisms including endoplasmic reticulum (ER) stress, unfolded protein response 
(UPR) and inhibition of pro-apoptotic pathways initiated in mitochondria $(1,3)$. ER stress is activated when the ER chaperones involved in the refolding of misfolded proteins are not functional leading to the accumulation of high levels of misfolded proteins in the cell and subsequent induction of UPR (4). By activating ER stress, the cells transiently halt protein synthesis in order to cope with the accumulation of non-functional proteins but if the concentration of the misfolded proteins is high the UPR stimulates cell death $(5,6)$.

Redox responsive endoplasmic reticulum proteins such as members of the protein disulfide isomerase (PDI) superfamily and in particular the prototype family member prolyl 4-hydroxylase subunit beta (P4HB or PDIA1) activates the ER transmembrane kinase protein kinase R (PKR)-like endoplasmic reticulum kinase (PERK) thus playing a crucial role in the stimulation of the UPR (7). PDIA1 has been shown to modulate cellular oxidative stress mediating homeostasis of the antioxidant glutathione (8) and its function is regulated by cellular redox state. Specifically, PDIA1 exerts chaperone and isomerase activities in an oxidative stress-dependent manner facilitating redox-mediated regulation of protein folding (9-12).

PDIA1 is primarily localized in the endoplasmic reticulum but extracellular matrix, mitochondria, nucleus, and cytosolic PDIA1 localization has also been demonstrated (13). Diverse subcellular localization confers PDIA1 a dual role in cell death and survival during ER stress (14). For instance, PDIA1 mitochondrial localization contributes to the induction of mitochondrial outer membrane permeabilization (MOMP), the release of the mitochondrial cytochrome $\mathrm{c}$ into the cytoplasm and the initiation of apoptosis (15). Furthermore, PDIA1 mitochondrial localization suggested that this protein is involved in the regulation of redox mediated mitochondrial functions including energy metabolism (16). Nuclear localization of PDIA1 implicated this protein in the regulation of the activity of redox-sensitive transcription factors to co-ordinate efficient ROS detoxification (17). Extracellular matrix localization of PDIA1 was potentially related to invasion and metastasis as it has been shown for PDI family members in glioma (18) and hepatocarcinoma (14).

The impact of ER stress on immune responses (19) as well as the involvement of the UPR in the regulation of the tumor microenvironment are becoming widely acknowledged (20). PDI family members are key components of the antigen presentation machinery $(21,22)$ contributing to the selection and loading of the optimal antigen to MHC class I molecules $(23,24)$ and the dissociation of the antigen-loaded MHC class I complex and exit from the endoplasmic reticulum (25).

In the present study, the regulation of the PDIA1 functions under diverse oxidative stress conditions and its role in a range of physiological processes known to affect breast carcinogenesis were investigated in the estrogen receptor (ER $\alpha)$-positive $\mathrm{MCF}-7$ and the triple negative MDA-MB-231 breast cancer cells. The correlation between PDIAl and $H L A-G$ mRNA levels and their association with the overall survival were also investigated in breast cancer patients by analyzing the molecular taxonomy of breast cancer international consortium (METABRIC) microarray dataset available in the cBio cancer genomics portal (http://cbioportal.org) (26).

The results provide evidence to support the view that PDIAI differentially affects antioxidant homeostasis and ATP generation in the ER $\alpha$-positive vs. the TNBC cells and its mRNA levels are linked to the overall survival of stage 2 breast cancer patients. The findings of this study indicate an alternative molecular mechanism directing the evasion of immune surveillance in breast tumors that could be used as a platform for the design of stratified breast cancer immunotherapies, in addition to those that use PDIA1 as a therapeutic target (27).

\section{Materials and methods}

Cell culture. The human breast carcinoma cell lines MCF-7 (expressing wild-type p53) and MDA-MB-231 [bearing mutated p53 (R280K)] were obtained from the European collection of cell cultures (ECACC) and maintained in Dulbecco's modified Eagle's medium (Sigma-Aldrich, UK) supplemented with $10 \%$ foetal bovine serum (Gibco) and $1 \%$ penicillin/streptomycin (Lonza) at $37^{\circ} \mathrm{C}$ in a humidified atmosphere containing $5 \% \mathrm{CO}_{2}$ until they reached $70 \%$ confluency $(48 \mathrm{~h})$. Where indicated cells were treated with $10 \mathrm{ng} / \mathrm{ml}$ interferon- $\gamma($ IFN- $\gamma$ ) (Sigma-Aldrich) for $24 \mathrm{~h}$ or $10 \mu \mathrm{M}$ etoposide (ETOP) for $24 \mathrm{~h}$ (Sigma-Aldrich).

Western blotting. Cellular extracts from MCF-7 and MDA-MB-231 were collected in ice-cold TNNbuffer containing $1 \mathrm{mM}$ DTT, $1 \mathrm{mM}$ PMSF, and $1 \mu \mathrm{g} / \mathrm{ml}$ protease inhibitors. Protein concentrations were determined by the Bradford assay (Sigma Aldrich) and $30 \mu \mathrm{g}$ of protein per sample were resolved on a $20 \%$ precast polyacrylamide gel and transferred to a PVDF membrane. The membranes were blocked using $5 \%$ fat-free milk in PBS (v/v) for $1 \mathrm{~h}$ at $25^{\circ} \mathrm{C}$. Membranes were then incubated in $2.5 \%$ milk in PBS-0.1\% Tween-20 (v/v) with anti-P4HB antibody (Santa Cruz Biotechnology; sc-136230) (dilution 1:500) or $\beta$-actin (Sigma Aldrich; A1978) (dilution $1: 10,000)$ overnight at $4^{\circ} \mathrm{C}$. The membranes were washed three times with PBS-0.1\% Tween-20 (v/v) for $5 \mathrm{~min}$ and then incubated with secondary anti-mouse immunoglobulin $G$ conjugated to horsedish peroxidase (GE Healthcare) (dilution $1: 1,000)$ in $2.5 \%$ milk in PBS-0.1\% Tween-20 (v/v) for $1 \mathrm{~h}$ at $25^{\circ} \mathrm{C}$. Protein bands were then visualized using the ChemiDoc MP imaging system (Bio-Rad).

siRNA transfection. A concentration of $5 \mu \mathrm{M}$ of the SiGENOME P4HB siRNA and $5 \mu \mathrm{M}$ of the siGENOME non-targeting siRNA pool was added to each well containing $2 \times 10^{5}$ cells in DMEM and incubated for $72 \mathrm{~h}$ according to the suppliers' instructions (Dharmacon) as described previously (28). Immediately after the $72 \mathrm{~h}$ transfection cells were used for subsequent experimentation. The sequences of the siRNA pools against P4HB and scramble siRNA were: P4HB: ACAGGACGGUCAUUGAUUA, GGACGGUCAUUGAUU ACAA, CCAAGAGUGUGUCUGACUA, CAGAGAGGA UCACAGAGUU and scramble: UAGCGACUAAACACA UCAA, UAAGGCUAUGAAGAGAUAC, AUGUAUUGG CCUGUAUUAG, AUGAACGUGAAUUGCUCAA.

Intracellular ROS generation. ROS generation was measured using the dye CM- $\mathrm{H}_{2} \mathrm{DCF}-\mathrm{DA}$ (29). Briefly, cells were grown in 6 -well plates at a density of $1 \times 10^{6}$ cells/well and treated as indicated. Cells were centrifuged for $3 \mathrm{~min}$ at $400 \mathrm{x} \mathrm{g}$ at $25^{\circ} \mathrm{C}$, the supernatant was removed and the pellet resuspended 
in cold PBS. Then, $1 \mu \mathrm{M}$ of CM- $\mathrm{H}_{2}$ DCF-DA was added and the extracts were incubated for $30 \mathrm{~min}$ in the dark at $25^{\circ} \mathrm{C}$. Subsequently, $30 \mu 1$ of samples were transferred to A2 slides (ChemoMetec) and ROS were measured using the NucleoCounter NC-3000 ${ }^{\mathrm{TM}}$ (ChemoMetec).

Glutathione cellular levels. The NucleoCounter NC-3000 ${ }^{\mathrm{TM}}$ system was used to detect changes in the intracellular level of (reduced) thiols. Following the indicated treatments cells were dissociated from the culture plates using $500 \mu \mathrm{l}$ dissociation buffer (ChemoMetec). Then the cells were stained with solution 5 according to the manufacturer's instructions (ChemoMetec), loaded onto 8-chamber NC-slides and samples were analysed using the NucleoCounter NC-3,000 ${ }^{\mathrm{TM}}$.

Mitochondrial membrane disruption. Mitochondrial transmembrane disruption was measured using the cationic dye JC-1 (5,5,6,6-tetrachloro-1,1,3,3-tetraethyl benzimidazol carbocyanine iodide) (ChemoMetec) and the NucleoCounter $\mathrm{NC}-3,000^{\mathrm{TM}}$. Following the indicated treatment, the cells were stained with JC-1 and DAPI according to the manufacturer's instructions (ChemoMetec). Cellular JC-1 monomers and aggregates were detected as green and red fluorescence, respectively. Mitochondrial depolarization and apoptosis were revealed as a decrease in the ratio of red/green fluorescence. Staining with the blue fluorescent dye (DAPI) was used to detect necrotic and late apoptotic cells. After stained cells were loaded on an 8-chamber NC-Slide $\mathrm{A} 8^{\mathrm{TM}}$ and samples were analysed quantifying the amount of blue, green, and red fluorescence using the NucleoCounter NC-3,000 ${ }^{\mathrm{TM}}$.

Adenosine triphosphate assay. ATP levels were measured using the ViaLight plus kit (Lonza), based on the amount of bioluminescent ATP generated in cells. ATP monitoring reagent (AMR plus) was prepared by adding assay buffer into the vial containing the lyophilized AMR and incubated at room temperature for $15 \mathrm{~min}$ for complete rehydration. Cells were lysed in $50 \mu \mathrm{l}$ and the cell lysate was added to a luminometer plate together with $100 \mu \mathrm{l}$ of cell lysis reagent for $10 \mathrm{~min}$. A total volume of $100 \mu \mathrm{l}$ of AMR plus was added to the appropriate well. The plate was then incubated at room temperature for $2 \mathrm{~min}$ and luminescence values were obtained using the Fluostar OPTIMA microplate reader (BMG Labtech).

HLA-G surface levels. Breast cancer cell lines were seeded in a 6-well plate at a concentration of $1 \times 10^{6}$ cancer cells/well for $24 \mathrm{~h}$ in a $\mathrm{CO}_{2}$ incubator. Cells were then transfected with P4HB siRNA or scramble siRNA for $48 \mathrm{~h}$ at $37^{\circ} \mathrm{C}$. Following treatment with IFN- $\gamma$ or ETOP for $24 \mathrm{~h}$ at $37^{\circ} \mathrm{C}$, the cells were detached from the wells with $500 \mu \mathrm{l}$ dissociation buffer and the cell lysates were transferred to a $15 \mathrm{ml}$ falcon tube and centrifuged at $300 \mathrm{x}$ g for $5 \mathrm{~min}$ at $4^{\circ} \mathrm{C}$. The supernatant was removed and $3 \times 10^{5}$ cells in $100 \mu 1$ (10\% FBS in PBS) were transferred to a fresh tube. APC-anti human HLA-G (Thermo Fisher) was added and the cells were incubated for $30 \mathrm{~min}$ on ice in the dark. The stained samples were analysed by flow cytometry (Becton Dickinson).

PDIA1-HLA-G correlation in breast cancer patients. The METABRIC breast cancer dataset was downloaded from
cBio Cancer Genomics Portal (http://cbioportal.org) for 1,900 breast cancer patients (26). The distribution of the mRNA expression levels of PDIAI and $H L A-G$ was measured across samples. PDIAI (P4HB) and HLA-G mRNA expression levels were considered high if their z-scores were higher or equal to the 75th percentile of the distribution (30) and low if their $\mathrm{z}$-scores were lower than the 75 th percentile of the distribution (z-score high $P D I A \geq 0.572$, z-score high $H L A-G \geq 0.517)$.

Statistical analysis. Graphs were plotted using GraphPad PRISM 7 (GraphPad software Inc.). The Mann-Whitney test was used to assess the significance of the difference between two groups, whereas the Kruskal-Wallis test was used to assess the significance of the differences between more than two groups. Log-rank was used to test the significance of the difference between Kaplan-Meier survival curves. The mean was calculated as \pm SEM. $\mathrm{P}<0.05$ indicated statistical significance.

\section{Results}

Silencing of PDIA1 gene expression in breast cancer cells. To investigate the role of the PDIA1 in the modulation of diverse hallmarks of cancer such as resistance to cell death, regulation of cellular energy production pathways and evasion of immune destruction, the gene expression of this oxidoreductase was silenced in the ER $\alpha$-positive (MCF-7) and the ER $\alpha$-negative (MDA-MB-231) breast cancer cells. The efficiency of silencing of the PDIAI gene expression was confirmed for each assay performed. The representative western blot analysis shown in Fig. 1, which shows the efficient silencing of the PDIAl gene expression only in MCF-7 and MDA-MD-231 cells transfected with the siRNA-PDIA1 untreated or treated with IFN- $\gamma$ or ETOP, but not in those cells transfected with the scramble siRNA.

PDIA1 modulates ROS generation in breast cancer cells. Type II interferon IFN- $\gamma$ induces both carcinogenic and cytotoxic effects (31) playing an important role in cell growth and survival in a manner involving the generation of ROS (32). The topoisomerase II inhibitor ETOP has also been shown to induce ROS generation in brain cancer cells (33). Additionally, IFN- $\gamma$ regulates the expression of genes encoding NADPH oxidases (Nox) (34) and evidence indicating functional interaction between PDI and Nox family members (35) suggests that IFN- $\gamma$ may indirectly regulate PDIA1 levels and activity under diverse oxidative stress conditions. The association between overexpression of NADPH oxidases and resistance to ETOP treatment as a result of ROS-mediated induction of senescence has also been reported (36), suggesting that PDIA1 is a potential indirect modulator of ROS mediated effects exerted upon ETOP treatment. To investigate the potential involvement of PDIA1 in altering the IFN- $\gamma$ and ETOP mediated redox state in breast cancer cells ROS levels were measured in MCF-7 and MDA-MB-231 cells treated with these compounds in the presence or absence of PDIA1.

In MCF-7 cells silencing of PDIA1 did not affect ROS generation in the untreated or IFN- $\gamma$ treated cells compared to scramble-transfected cells (Fig. 2A, compare bars 1 and 3 
A
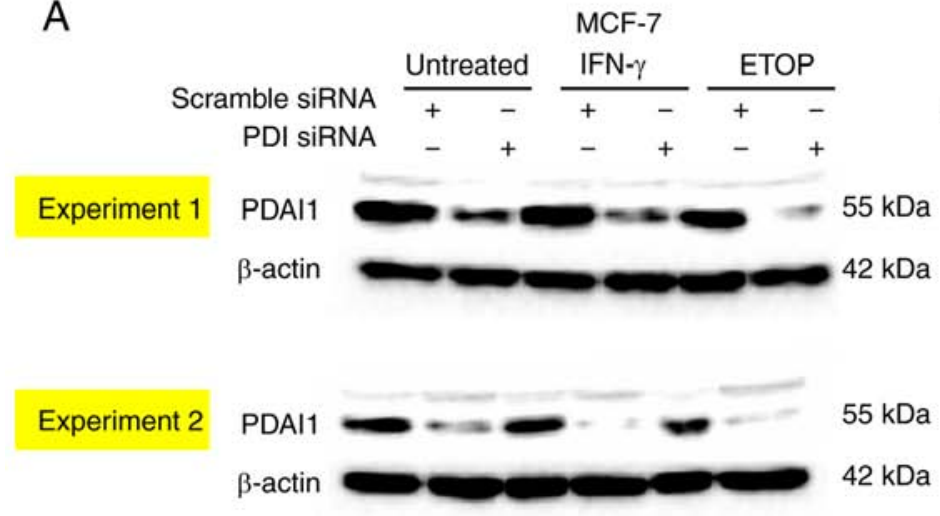

$55 \mathrm{kDa}$

$42 \mathrm{kDa}$

B
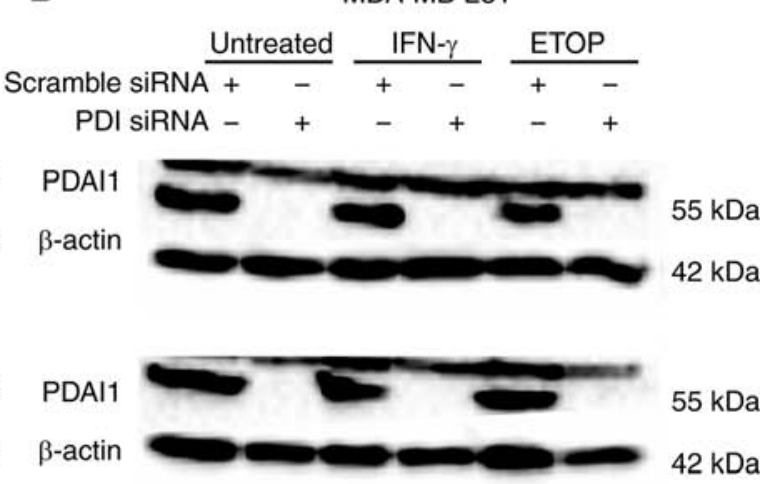

Experiment 3

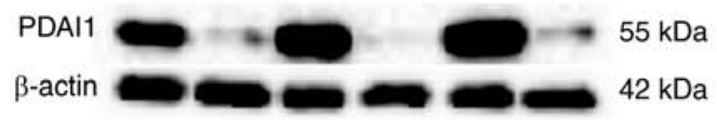

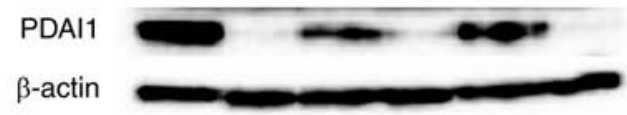

$55 \mathrm{kDa}$

$42 \mathrm{kDa}$

Figure 1. Silencing of PDIA1 gene expression in breast cancer cells. MCF-7 (A) and MDA-MD-231 (B) cells were transfected with either scramble or siRNA-PDAI1 and treated with DMSO, IFN- $\gamma$ or ETOP as indicated. The silencing efficiency was evaluated using western blot analysis.

to bars 2 and 4, respectively). Decreased ROS levels were recorded in PDIA1-silenced MCF-7 cells treated with ETOP compared to scramble-transfected cells under the same conditions (Fig. 2A, compare bar 5 to bar 6). Decreased ROS levels were measured in MCF-7 cells treated with IFN- $\gamma$ in the presence of PDIA1 compared to the untreated cells (Fig. 2A, compare bar 3 to bar 1) whereas in the presence of PDIA1 ETOP did not affect ROS generation in MCF-7 cells (Fig. 2A compare bar 5 to bar 1). In the absence of PDIA1 significantly decreased ROS generation was observed in the ETOP-treated MCF-7 cells compared to untreated cells (Fig. 2A, compare bar 6 to bar 2). Significantly increased ROS levels were observed in PDIA1-silenced MDA-MB-231 cells treated with either IFN- $\gamma$ or ETOP compared to the scramble-transfected cells under the same conditions (Fig. 2C, compare bars 3 and 5 to bars 4 and 6, respectively). Significantly decreased ROS levels were observed in the IFN- $\gamma$ treated MDA-MB-231 cells in the presence of PDIA1 compared to untreated cells under the same conditions (Fig. 2C, compare bar 3 to bar 1). ETOP treatment of PDIA1-silenced MDA-MB-231 cells resulted in a significant increase of ROS generation compared to untreated cells (Fig. 2C, compare bar 6 to bar 2). PDIA1 protein levels were not significantly affected by any treatment (Fig. 1). Representative histograms showing the ROS levels in scramble or siRNA-PDIA1-transfected MCF-7 or MDA-MB-231 cells untreated or treated with IFN- $\gamma$ or ETOP are provided in Fig. 2B and 2D, respectively.

PDIAl regulates GSH levels in breast cancer cells. The ratio of glutathione (GSH) vs. glutathione disulfide (GSSG) is important for cellular physiology since a decreased GSH/GSSG ratio leads to increased susceptibility to oxidative stress whereas increased GSH levels induce resistance of cancer cells to oxidative stress (37). Inhibition of PDIA1 isomerase activity has been shown to abrogate glutathione depletion (8) indicating the essential role of PDIA1 in the process of disulfide bond formation and therefore the regulation of the ratio of GSH vs. GSSG (38). To investigate the role of PDIA1 in the regulation of the GSH homeostasis in breast cancer cells the GSH/GSSG ratio was investigated in MCF-7 and MDA-MB-231 cells in which the PDIAI expression had been silenced.

Significant upregulation of GSH levels was observed in the untreated PDIA1-silenced MCF-7 cells compared to scramble-transfected cells under the same conditions (Fig. 3A, compare bar 1 to bar 2). There were no other changes evident in GSH levels in MCF-7 cells in any of the conditions studied (Fig. 3A). By contrast, in the MDA-MB-231 cells significant downregulation of GSH levels was observed in the untreated PDIAI-silenced MDA-MB-231 cells compared to the untreated and scramble-transfected cells (Fig. 3C, compare bar 1 to bar 2). Downregulation of GSH levels was also recorded in the ETOP-treated MDA-MB-231 cells in the presence of PDIAl compared to the untreated cells (Fig. 3C, compare 5 to bar 1). Finally upregulated GSH levels were measured in PDIA1 silenced MDA-MB-231 cells treated with IFN- $\gamma$ compared to the siRNA-PDIA1 transfected untreated cells (Fig. 3C, compare bar 4 to bar 2). Representative histograms showing the GSH levels in scramble or siRNA-PDIA1 transfected MCF-7 or MDA-MB-231 are provided in Fig. 3B and 3D respectively.

PDIA1 regulates mitochondrial function in breast cancer cells. The communication between ER and mitochondria is critical for several important cellular functions including the balance between survival and death (39). The role of PDIA1 in the regulation of this communication has been shown in cells in which blocking the PDIA1 activity prevents stimulation of the mitochondrial outer membrane potential (MOMP) and inhibits apoptosis (15). In addition, the combination of ETOP with a PDI inhibitor has been shown to trigger increased ER-associated calcium influx and loss of mitochondrial membrane integrity (40). These findings led us to investigate the effect of PDIA1 on the integrity of the mitochondrial membrane of breast cancer cells. 


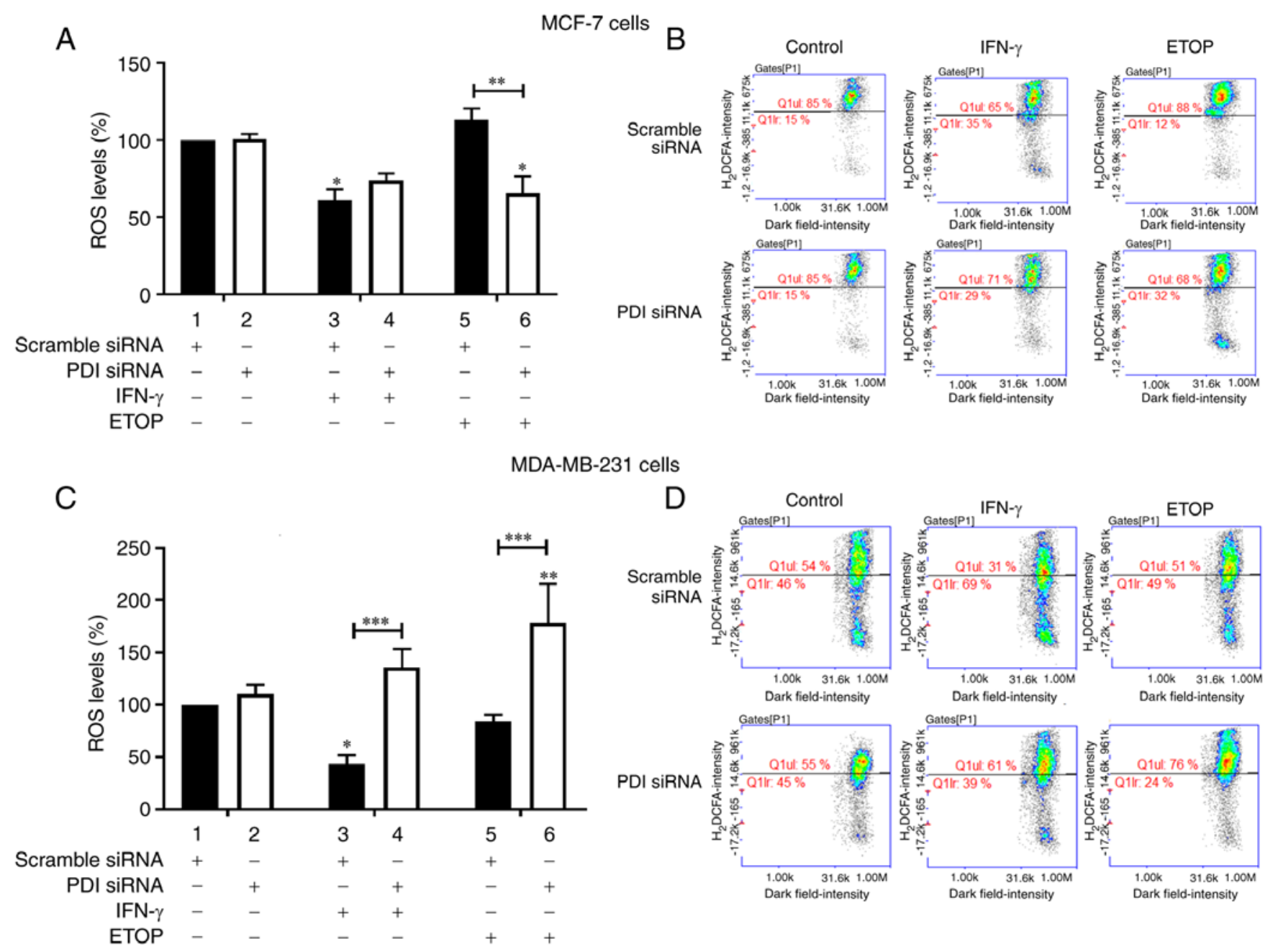

Figure 2. ROS generation in untreated, IFN- $\gamma$ or ETOP treated breast cancer cells in the presence or absence of PDIA1. (A and C) Bar chart represent the ROS levels in siRNA scramble transfected (black bars) or siRNA-PDIA1 transfected (white bars) MCF-7 (A) or MDA-MB-231 (C) cells untreated or treated with either IFN- $\gamma$ or ETOP as indicated. ROS levels recorded in the scramble transfected and untreated cells were arbitrarily set to 100 and the different treatments were calculated accordingly. The asterisks above each bar indicate the statistical significance of the comparison between bars 3 and 5 compared to bar 1 and bars 4 and 6 compared to bar 2. The asterisks above the line indicate the comparison between black and white bars. (B and D) Representative histograms showing the ROS levels in scramble or siRNA-PDIA1 transfected MCF-7 (B) or MDA-MB-231 (D) cells untreated or treated with IFN- $\gamma$ or ETOP. The data represent the mean of three independent experiments and the error bars the mean $\pm \mathrm{SEM} .{ }^{*} \mathrm{P}<0.05,{ }^{* *} \mathrm{P}<0.01$ and ${ }^{* * * *} \mathrm{P}<0.005$.

The mitochondrial membrane potential was investigated in MCF-7 and MDA-MB-231 cells in which the PDIAI expression had been silenced and cells were left untreated or treated with IFN- $\gamma$ or ETOP. Silencing of PDIA1 in MCF-7 cells downregulated mitochondrial membrane potential in the untreated cells compared to the scramble-transfected cells under the same conditions (Fig. 4A, compare bar 1 to bar 2). Increased mitochondrial membrane potential was observed in the presence of PDIA1 in MCF-7 cells treated with IFN- $\gamma$ compared to the untreated cells (Fig. 4A, compare bar 3 to bar 1), whereas decreased mitochondrial membrane disruption was measured in the presence of PDIAl in MCF-7 cells treated with ETOP compared to the untreated cells (Fig. 4A, compare bar 5 to bar 1). PDIAI-silenced MCF-7 cells treated with IFN- $\gamma$ exhibited increased mitochondrial membrane disruption compared to PDIA1-silenced untreated cells (Fig. 4A, compare bar 4 to bar 2). Silencing of PDIAl in MDA-MB-231 cells upregulated mitochondrial membrane disruption in ETOP-treated cells compared to the scramble-transfected cells under the same conditions (Fig. 4C, compare bar 5 to bar 6).
Increased mitochondrial membrane disruption levels were also measured in MDA-MB-231 cells treated with IFN- $\gamma$ in the presence of PDIA1 compared to the untreated cells (Fig. 4C, compare bar 3 to bar 1). In ETOP-treated PDIAl-silenced MDA-MB-231 cells the mitochondrial membrane disruption was upregulated compared to the untreated cells under these conditions (Fig. 4C, compare bar 6 to bar 2). Representative histograms showing the intensity of JC-1 (\%) in scramble or siRNA targeting PDIA1-transfected MCF-7 and MDA-MB-231 cells are provided in Fig. 4B and 4D, respectively.

PDIA1 modulates energy metabolism in breast cancer cells. The communication between ER and mitochondria by a network of proteins residing in the interface between the two organelles is critical in controlling vital physiological functions including energy metabolism and cellular death/survival decisions (41). Structural and functional changes of the ER-mitochondria contact proteins result in the deregulation of calcium $\left(\mathrm{Ca}^{2+}\right)$ homeostasis and consequently mitochondrial energy production and cell death (42). PDI plays an important 
A

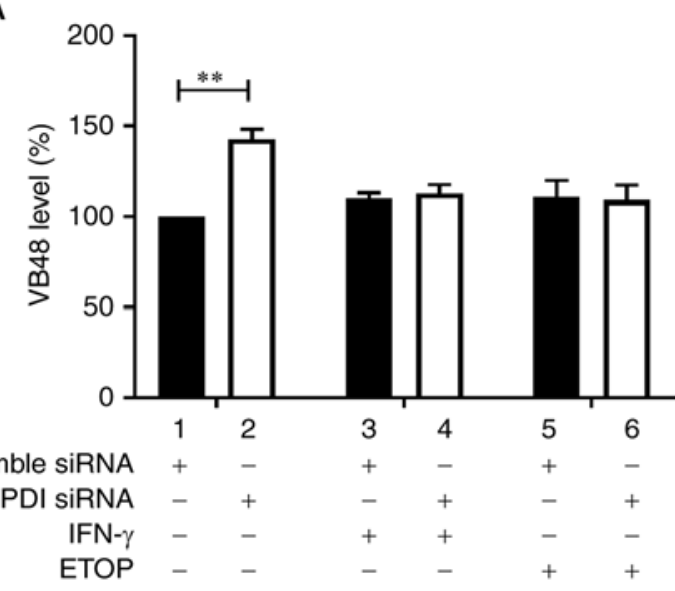

MCF-7 cells
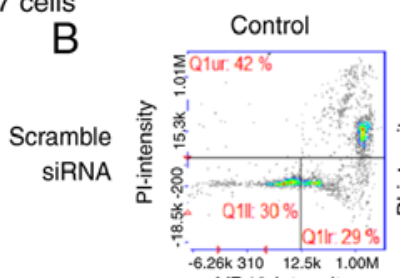

VB48-intensity
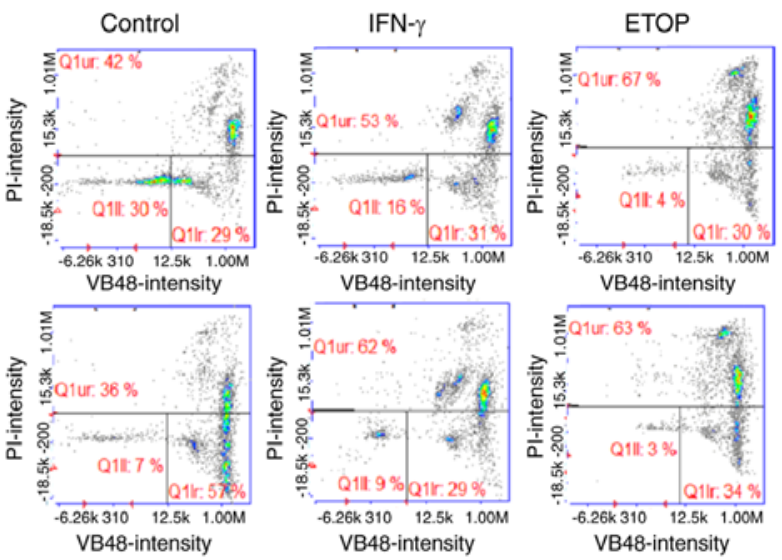

MDA-MB-231 cells

C

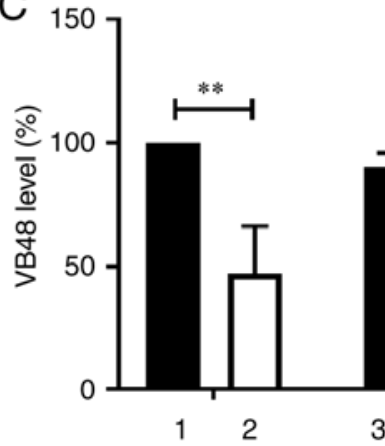

D
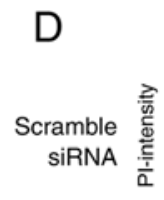

Control

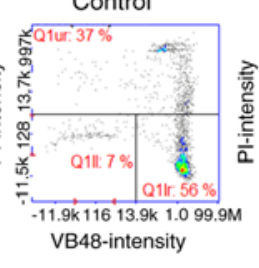

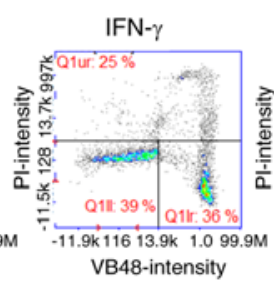

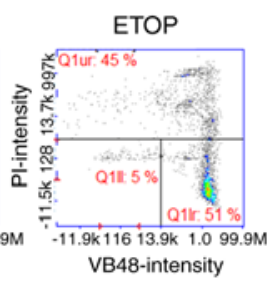

PDI SiRNA
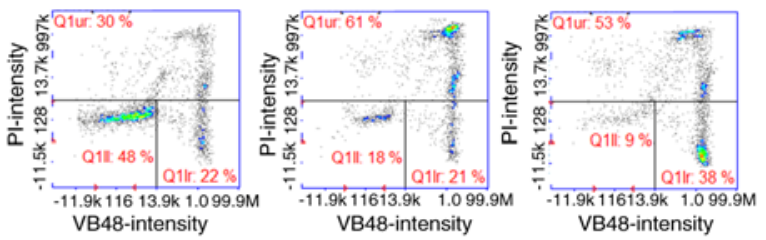

PDI SiRNA

IFN- $\gamma$

ETOP

Figure 3. GSH levels in untreated, IFN- $\gamma$ or ETOP treated breast cancer cells in the presence or absence of PDIA1. (A and C) Bar charts represent GSH levels in MCF-7 (A) and MDA-MD-231 (C) cells in the presence (black bars) or absence of PDIA1 (white bars) untreated or treated with IFN- $\gamma$ or ETOP as indicated. GSH levels detected in the scramble transfected and untreated cells were arbitrarily set to 100 and the different treatments were calculated accordingly. The asterisks above each bar indicate the statistical significance of the comparison between bars 3 and 5 compared to bar 1 and bars 4 and 6 compared to bar 2 . The asterisks above the line indicate the comparison between black and white bars. (B and D) Representative histograms showing the GSH levels in siRNA scramble or PDIA1 transfected MCF-7 (B) or MDA-MB-231 (D) cells. The data represent the mean of three independent experiments and the error bars the mean \pm SEM. ${ }^{*} \mathrm{P}<0.05$ and ${ }^{* *} \mathrm{P}<0.01$.

role in the cross talk between cellular redox state and $\mathrm{Ca}^{2+}$ homeostasis in the ER (43) suggesting its involvement in the regulation of energy metabolism (44).

To test this hypothesis ATP production was investigated in MCF-7 and MDA-MB-231 cells treated with IFN- $\gamma$ or ETOP in the presence or absence of PDIAI (Fig. 5). Silencing of PDIA1 in MCF-7 cells upregulated ATP levels in the untreated cells (Fig. 5A, compare bar 1 to bar 2). Decreased ATP levels were recorded in MCF-7 cells treated with IFN- $\gamma$ or ETOP in the presence of PDIA1 compared to the untreated cells (Fig. 5A, compare bars 3 and 5 to bar 1). Decreased ATP levels were also observed in PDIA1-silenced MCF-7 cells treated with IFN- $\gamma$ (Fig. 5A, compare bar 3 to bar 4) or ETOP compared to scramble-transfected cells under the same conditions (Fig. 5A, compare bar 5 to bar 6). Overall, no significant changes in ATP levels were evident in untreated, IFN- $\gamma$ - or ETOP-treated PDIA1-silenced MCF-7 cells compared to those measured in the untreated, IFN- $\gamma$ or ETOP treated cells in the presence of PDIA1 (Fig. 5B)

Decreased ATP levels were measured in MDA-MB-231 cells treated with IFN- $\gamma$ or ETOP in the presence of PDIAI compared to the untreated cells (Fig. 5C, compare bars 3 and 5 to bar 1). Silencing of PDIA1 in MDA-MB-231 cells downregulated ATP levels in the untreated cells (Fig. 5C, compare bar 1 to bar 2), IFN- $\gamma$-treated cells (Fig. 5C, compare bar 3 to bar 4), and ETOP-treated cells (Fig. 5C, compare bar 5 to bar 6). ATP generation was downregulated significantly in untreated, IFN- $\gamma$ - or ETOP-treated MDA-MB-231 cells in the absence of PDIAl vs. the presence of PDIAl (Fig. 5D).

PDIA1 modulates HLA-G surface levels in breast cancer cells. In recent years, the connection between ER stress signalling pathways, UPR induction, deregulation of energy metabolism, and immune responses has been unravelled $(45,46)$. The link between the cellular redox state with several ER-resident chaperones and in particular PDIA1 in mediating the processing, optimal selection and antigen loading to the MHC class I during the process of antigen presentation have been demonstrated $(23,24,47)$. Apart from the peptide antigen processing, loading and stabilization of the early MHC class I complex (22), PDIA1 has also been shown to modulate the 
A

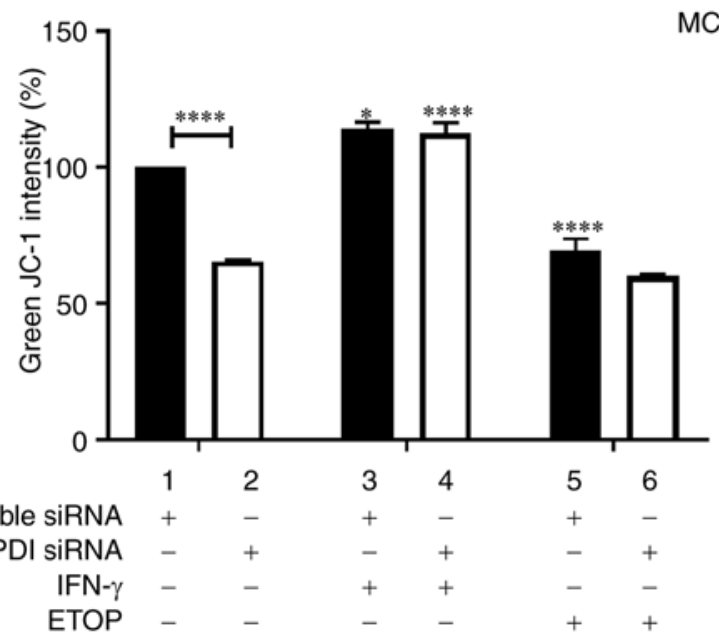

MCF-7 cells

B

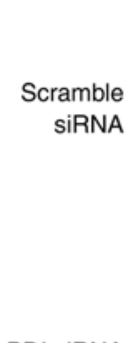

PDI SiRNA
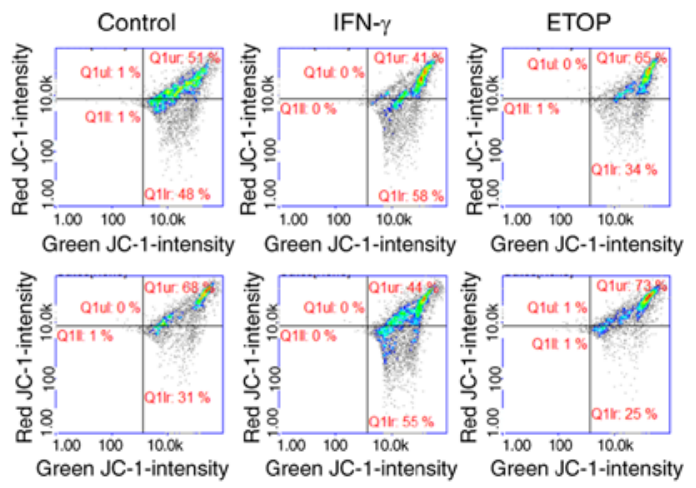

MDA-MB-231 cells

C

D
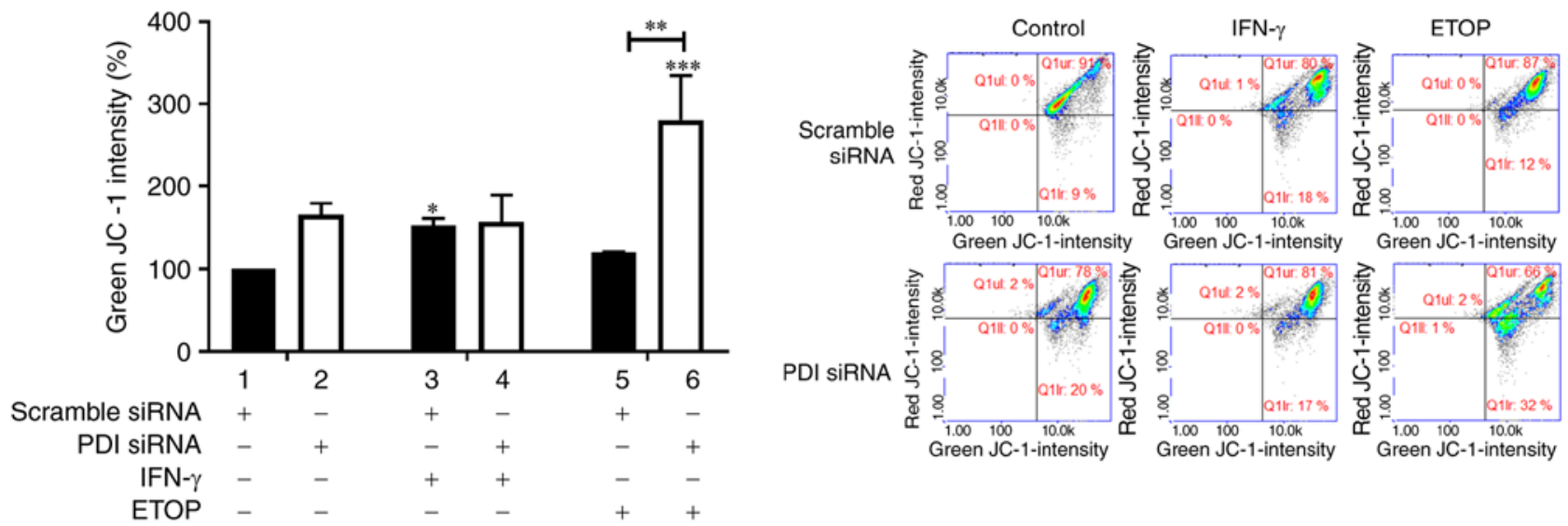

Figure 4. Mitochondrial membrane potential in untreated, IFN- $\gamma$ or ETOP-treated breast cancer cells in the presence or absence of PDIA1. (A and C) Bar charts represent the mitochondrial membrane disruption levels in siRNA scramble transfected (black bars) or siRNA-PDIA1 transfected (white bars) MCF7 (A) and MDA-MB-231 (C) cells untreated or treated with IFN- $\gamma$ or ETOP as indicated. The mitochondrial membrane disruption levels in the scramble transfected and untreated cells were arbitrarily set to 100 and the different treatments were calculated accordingly. The asterisks above each bar indicate the statistical significance of the comparison between bars 3 and 5 compared to bar 1 and bars 4 and 6 compared to bar 2. The asterisks above the line indicate the comparison between black and white bars. (B and D) Representative histograms showing the JC-1 (\%) intensity in scramble siRNA or siRNA targeting PDIA1 transfected MCF-7 (B) and MDA-MB-231 (D) cells. The data represent the mean of three independent experiments and the error bars the mean $\pm \mathrm{SEM}$. ${ }^{*}<0.05,{ }^{* *} \mathrm{P}<0.01$, **** $\mathrm{P}<0.005$ and $^{* * * *} \mathrm{P}<0.001$

MHC class I expression (48). Two types of the MHC class I molecules have been described; the classical (human leukocyte antigen HLA-A, HLA-B, and HLA-C alleles) and the non-classical (HLA-E, HLA-F, HLA-G) proteins (49). Human breast cancer tissues and breast cancer cells express HLA-G whereas in normal epithelial mammary cells HLA-G mRNA expression has not been detected indicating the involvement of the non-classical MHC class I molecules in the evasion of the immune surveillance by breast cancer cells and their important role in determining the prognosis of breast cancer patients (50-52).

To investigate any potential role of PDIA1 in modulating the surface expression of the non-classical MHC class I HLA-G molecule and thus in the process of evasion of immune surveillance $(51,52)$ the HLA-G surface levels were followed in untreated MCF-7 and MDA-MB-231 cells or treated with IFN- $\gamma$ or ETOP in the presence or absence of PDIAl (Fig. 6). Significantly lower HLA-G surface levels were observed in both MCF-7 and MDA-MB-231 cells in the absence of PDIAI compared to MCF-7 and MDA-MB-231 cells in the presence of PDIAl (Fig. 6A and B).

PDIA1/HLA-G mRNA ratio correlates with overall survival in breast cancer patients. To explore the correlation between $P D I A I$ and $H L A-G$ gene expression and identify any potential clinical implications of the PDIAI and HLA-G ratio in breast cancer patient data obtained from the METABRIC dataset available in the cBio Cancer Genomics Portal (http://cbioportal.org) (26) were analyzed to follow the PDIAl and HLA-G mRNA levels in various stages of ER $\alpha$-positive and ER $\alpha$-negative breast cancer patients. Table I indicates the number of $\mathrm{ER} \alpha$-positive and ER $\alpha$-negative patients and the stage classification of their disease. Results shown in Fig. S1 indicate the PDIAl and HLA-G mRNA expression levels in ER $\alpha$-positive (Fig. S1A and B) and ER $\alpha$-negative (Fig. S1C and D) patients in each stage of the disease. The correlation between PDIAI and $H L A-G$ mRNA levels in ER $\alpha$-positive stage 1 (Fig. S2A), stage 2 (Fig. S2B) and stage 3 (Fig. S2C) patients indicates 
A
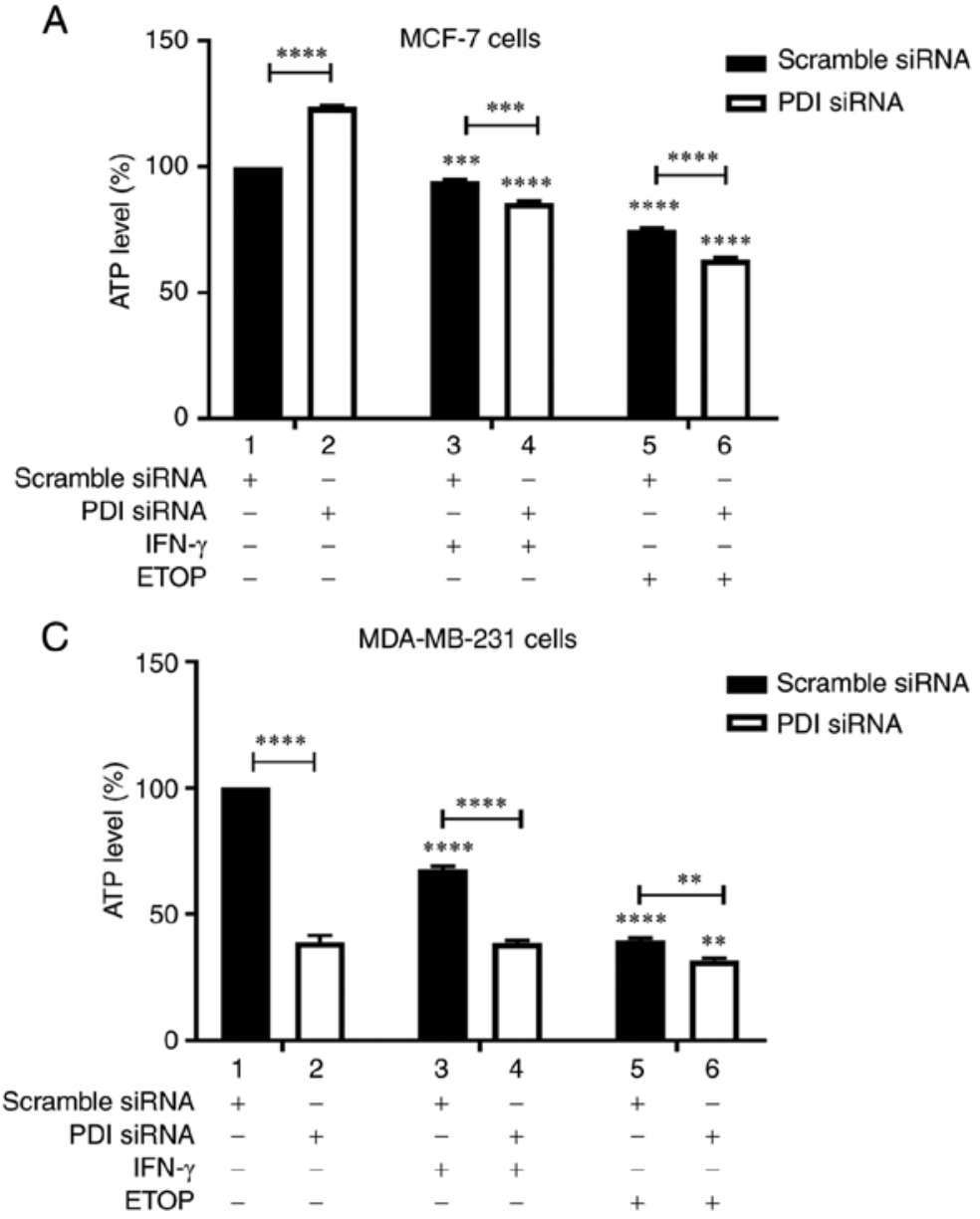

B Scramble siRNA PDI siRNA

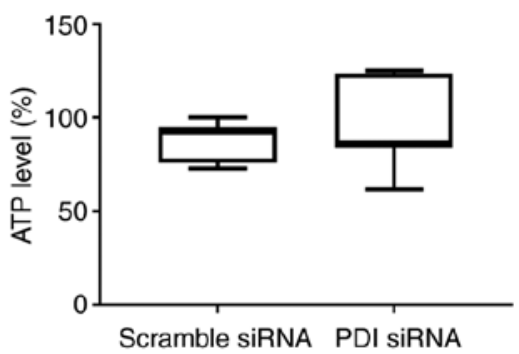

D MDA-MB-231 cells

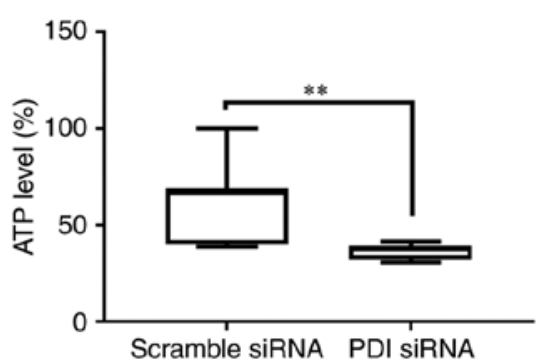

Figure 5. ATP levels in untreated, IFN- $\gamma$ or ETOP-treated breast cancer cells in the presence or absence of PDIA1. (A and C) Bar charts represent the ATP generation in scramble transfected (black bars) or siRNA PDIA1 transfected (white bars) MCF-7 (A) and MDA-MB-231 (C) cells untreated (bars 1 and 2) or treated with either IFN- $\gamma$ (bars 3 and 4) or ETOP (bars 5 and 6). ATP generation levels in the untreated control were arbitrarily set to 100 and the different treatments were calculated accordingly. The asterisks above each bar indicate the statistical significance of the comparison between bars 3 and 5 compared to bar 1 and bars 4 and 6 compared to bar 2. The asterisks above the line indicate the comparison between black and white bars. (B and D) Bar charts represent the average ATP generation levels in the non-treated, IFN- $\gamma$ and ETOP treated MCF-7 (B) and MDA-MB-231 (D) cells in the presence (scramble siRNA) or absence (PDIA1 siRNA) of PDIA1. The data represent the mean of three independent experiments and the error bars the mean $\pm \mathrm{SEM}$. ${ }^{* * *} \mathrm{P}<0.01,{ }^{* * * *} \mathrm{P}<0.005$ and ${ }^{* * * * *} \mathrm{P}<0.0001$.
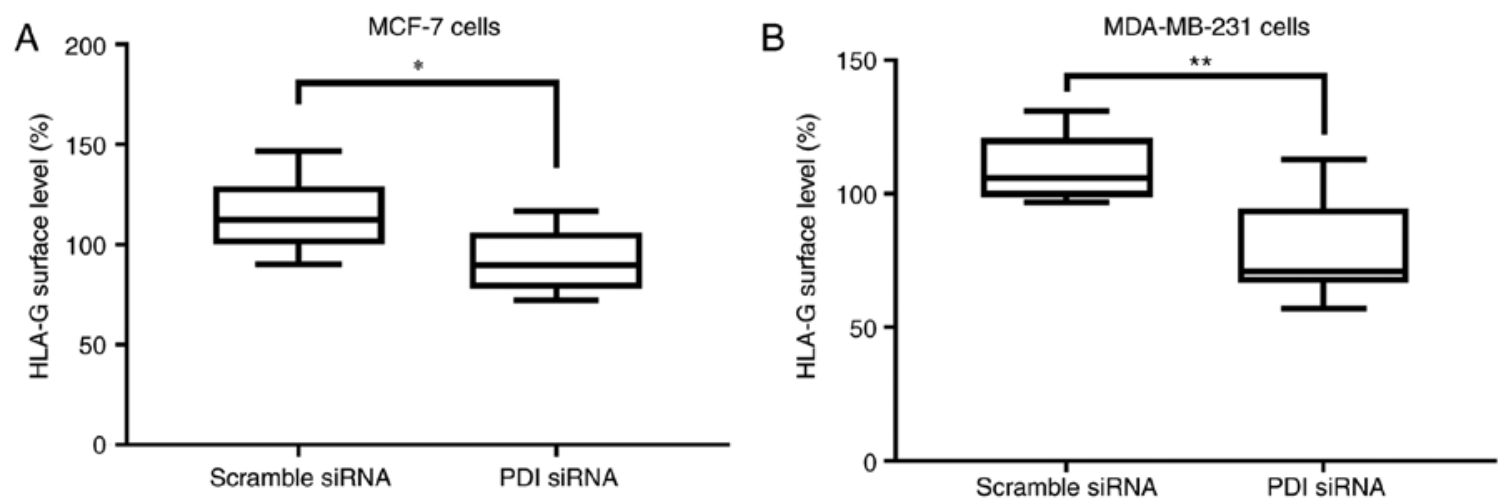

Figure 6. HLA-G levels in untreated, IFN- $\gamma$ or ETOP-treated breast cancer cells in the presence or absence of PDIA1. Bar charts represent the cell surface HLA-G levels in siRNA scramble transfected or siRNA PDIA1 transfected MCF-7 (A) and MDA-MB-231 (B) cells. The data represent the mean of three independent experiments and the error bars the mean \pm SEM. ${ }^{*} \mathrm{P}<0.05$ and ${ }^{* *} \mathrm{P}<0.01$.

statistically significant results for stage 2 and 3 patients. A similar analysis of the correlation between PDIAl and HLA-G mRNA levels in ER $\alpha$-negative stage 1 (Fig. S2D), stage 2 (Fig. S2E) and stage 3 (Fig. S2F) patients did not show any statistical significance. Kaplan-Meir survival curves were plotted to explore whether the PDIAI/HLA-G mRNA ratio was associated with the overall survival of stage 2 breast cancer patients (Fig. 7). Statistically significant association 
Table I. Breast cancer patient data obtained from the METABRIC microarray dataset categorized by ER $\alpha$ status, stage of the disease and levels of PDIA1 and HLA-G mRNA expression levels.

\begin{tabular}{|c|c|c|c|c|c|}
\hline \multicolumn{6}{|l|}{ METABRIC } \\
\hline \multirow[t]{17}{*}{ ER $\alpha$-positive } & \multirow{4}{*}{ Stage 1} & Not known & & 378 & 1,457 \\
\hline & & \multirow{2}{*}{ Low PDIA1 } & Low HLA-G & 265 & \\
\hline & & & High HLA-G & 59 & \\
\hline & & \multirow[t]{2}{*}{ HighPDIA1 } & Low HLA-G & 48 & \\
\hline & & & High HLA-G & 15 & \\
\hline & \multirow[t]{4}{*}{ Stage 2} & \multirow[t]{2}{*}{ Low PDIA1 } & Low HLA-G & 399 & \\
\hline & & & High HLA-G & 86 & \\
\hline & & \multirow[t]{2}{*}{ HighPDIA1 } & Low HLA-G & 92 & \\
\hline & & & High HLA-G & 38 & \\
\hline & \multirow[t]{4}{*}{ Stage 3} & \multirow[t]{2}{*}{ Low PDIA1 } & Low HLA-G & 38 & \\
\hline & & & High HLA-G & 15 & \\
\hline & & \multirow[t]{2}{*}{ HighPDIA1 } & Low HLA-G & 14 & \\
\hline & & & High HLA-G & 1 & \\
\hline & \multirow[t]{4}{*}{ Stage 4} & \multirow[t]{2}{*}{ Low PDIA1 } & Low HLA-G & 6 & \\
\hline & & & High HLA-G & 1 & \\
\hline & & \multirow[t]{2}{*}{ HighPDIA1 } & Low HLA-G & 2 & \\
\hline & & & High HLA-G & 0 & \\
\hline \multirow[t]{17}{*}{ ER $\alpha$-negative } & \multirow{5}{*}{ Stage 1} & \multicolumn{2}{|l|}{ Not known } & 123 & 443 \\
\hline & & Low PDIA1 & Low HLA-G & 27 & \\
\hline & & & High HLA-G & 24 & \\
\hline & & HighPDIA1 & Low HLA-G & 21 & \\
\hline & & & High HLA-G & 16 & \\
\hline & \multirow[t]{4}{*}{ Stage 2} & \multirow[t]{2}{*}{ Low PDIA1 } & Low HLA-G & 45 & \\
\hline & & & High HLA-G & 57 & \\
\hline & & \multirow[t]{2}{*}{ HighPDIA1 } & Low HLA-G & 51 & \\
\hline & & & High HLA-G & 32 & \\
\hline & \multirow[t]{4}{*}{ Stage 3} & \multirow[t]{2}{*}{ Low PDIA1 } & Low HLA-G & 18 & \\
\hline & & & High HLA-G & 13 & \\
\hline & & \multirow[t]{2}{*}{ HighPDIA1 } & Low HLA-G & 10 & \\
\hline & & & High HLA-G & 6 & \\
\hline & \multirow[t]{4}{*}{ Stage 4} & \multirow[t]{2}{*}{ Low PDIA1 } & Low HLA-G & 0 & \\
\hline & & & High HLA-G & 0 & \\
\hline & & \multirow[t]{2}{*}{ HighPDIA1 } & Low HLA-G & 0 & \\
\hline & & & High HLA-G & 0 & \\
\hline
\end{tabular}

Total

ER $\alpha$-positive or -negative breast cancer patients in stages 1-4 expressing high or low PDIA1 and HLA-G mRNA levels.

between low PDIA1/high HLA-G mRNA ratio and longer overall survival was observed in ER $\alpha$-negative stage 2 patients (Fig. 7D). Analysis of the subgroup of the living breast cancer patients at stage 2 exhibited low PDIA1 and high HLA-G mRNA ratio indicated that in the ER $\alpha$-positive patients longer survival is associated predominantly with high PDIA1 and low HLA-G mRNA levels (Fig. 7B) whereas in the ER $\alpha$-negative patients longer survival is associated mainly with low PDIAI and high HLA-G mRNA levels (Fig. 7E). A similar analysis carried out in the subgroup of the living breast cancer patients at stage 2 exhibiting high PDIA1 and low HLA-G mRNA levels indicated that longer survival was associated mainly with high PDIAl and low $H L A-G$ mRNA levels in the ER $\alpha$-negative patients (Fig. 7F) but there was no correlation in the ER $\alpha$-positive patients (Fig. 7C).

\section{Discussion}

Protein disulfide isomerases compose a superfamily of more than 20 members of endoplasmic reticulum proteins that apart from protein folding exert multiple other functions including oxidoreductase activity, molecular chaperoning and acting as hormone reservoirs (10). The prototype member of the family PDIA1 is localized primarily in the endoplasmic 

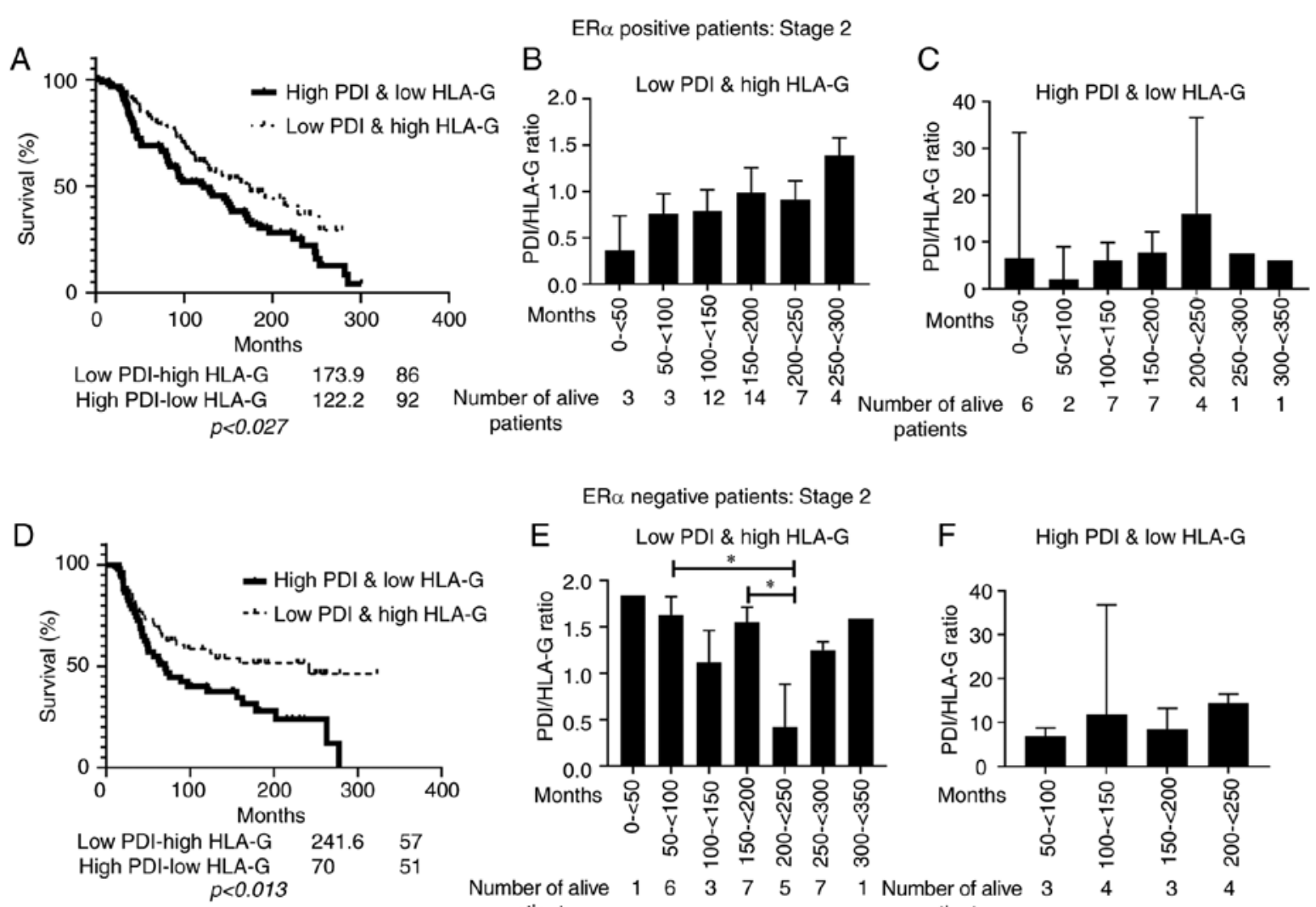

$E R \propto$ negative patients: Stage 2

E Low PDI \& high HLA-G F High PDI \& low HLA-G

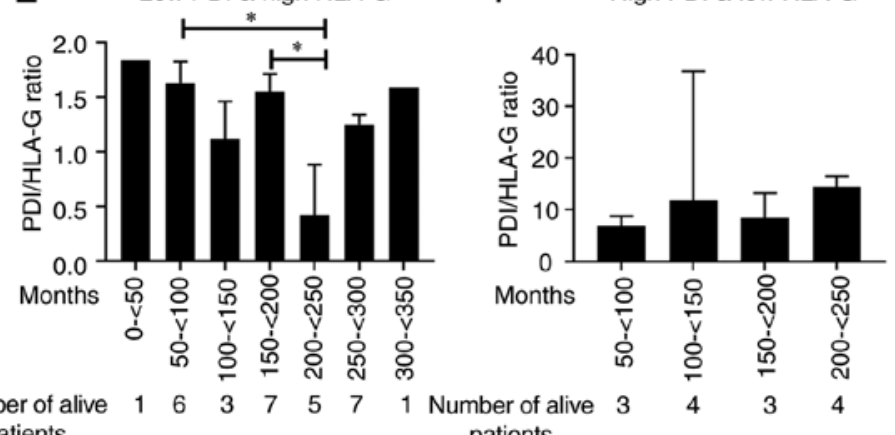

patients

patients

Figure 7. Kaplan-Meir survival curves showing the association of PDIA1 / HLA-G mRNA ratios with overall survival of stage 2 breast cancer patients. (A and D) Kaplan-Meir survival curves depicting the association between low PDIA1/high HLA-G and high PDIA1/low HLA-G mRNA ratios with overall survival of stage $2 \mathrm{ER} \alpha$ positive (A) and ER $\alpha$ negative (D) breast cancer patients. (B and E) Bar charts indicating the PDIAl/HLA-G mRNA ratio in the ER $\alpha$ positive (B) and ER $\alpha$ negative (E) patients exhibiting low PDIAl/high $H L A-G$ mRNA ratio. (C and F) Bar charts indicating the PDIA1/HLA-G mRNA ratio in the ER $\alpha$ positive (C) and ER $\alpha$ negative (F) patients exhibiting high PDIA1/low HLA-G mRNA ratio. ${ }^{*} \mathrm{P}<0.05$.

reticulum but nuclear, mitochondrial and localization on the surface of the cellular membrane has also been reported (43). PDIA1 exerts tumor-stimulating or suppressing effects being involved in a wide spectrum of physiological functions in a manner dependent on the type of tissue, microenvironmental conditions, subcellular localization and its oxidized or reduced conformation (10-12). To shed light on the role of the PDIA1 in breast carcinogenesis we followed a variety of ROS modulated pathways in the estrogen receptor positive MCF-7 and the ER $\alpha$ negative MDA-MB-231 cells under differential oxidative stress conditions in the presence or absence of PDIA1.

In the present study, IFN- $\gamma$ treatment reduced ROS levels in both MCF-7 and MDA-MB-231 cells whereas ETOP did not affect ROS generation in these cells in the presence of PDIA1. In the absence of PDIA1 IFN- $\gamma$ treatment did not affect ROS levels in MCF-7 cells and increased oxidative stress in MDA-MB-231 cells. Estrogen receptor alpha (ER $\alpha)$ and estrogen receptor beta (ER $\beta)$ associate with IFN- $\gamma$ and this association modulates malignant behaviour (53). In addition, PDIA1 interacts with ER $\alpha$ and regulates its structure and activity (54). Therefore the difference of the redox state between MCF-7 and MDA-MB-231 cells treated with IFN- $\gamma$ could be attributed to the fact that MCF-7 cells are ER $\alpha$ and ER $\beta$ positive whereas MDA-MB-231 cells are triple negative breast cancer cells. PDIA1 functions as ER $\alpha$ coregulator modulating the receptor's transcriptional activity (54). ER $\alpha$ modulates the gene expression of growth hormone $(G H)(55)$, which alters cellular oxidative stress levels (56). The differential regulation of the PDIA1-mediated $G H$ gene expression in the ER $\alpha$-positive MCF-7 cells and the ER $\alpha$-negative MDA-MB-231 cells is an additional potential explanation justifying the differential redox state in the ER $\alpha$ positive vs. the ER $\alpha$ negative breast cancer cells.

ETOP treatment, on the other hand, inhibited ROS generation in MCF-7 cells and induced oxidative stress in MDA-MB-231 cells in the absence of PDIAl suggesting that this topoisomerase II inhibitor exerts its effects through distinct pathways in the two cell lines. ETOP induces stabilization of the tumor suppressor p53 and PDI modifies the activity of this tumor suppressor (7) providing a potential explanation for the observed differences in ROS generation between the wild-type p53 expressing MCF-7 cells and the MDA-MB-231 cells which bear mutated p53 (p53-R280K). The gene expression of the NADPH oxidase family member Nox4, which is a source of ROS, has been demonstrated to be differentially regulated by wt and mutant p53 (57). Evidence indicating association between PDI and p53 (7) as well as PDI and Nox4 (58) has been previously presented suggesting that differences in the ROS levels generated in the MCF-7 compared to MDA-MB-231 could be attributed to the differential Nox4 levels in the two cell lines.

Glutathione is a known modulator of the function of PDIA1 (59) regulating the ratio of the oxidized vs. the reduced PDIA1 conformations (60). Oxidized and reduced PDIA1 
conformations or death outcome during ER stress (9) suggest the importance of the interplay between GSH and PDIA1 in cancer progression. Silencing of PDIAI increased cellular GSH concentration in MCF-7 cells whereas the opposite was the case in MDA-MB-231 cells where in the absence of PDIA1 decreased GSH levels were observed. Since depletion of cellular GSH is an indicator of apoptosis initiation (61), the obtained results indicate that PDIA1 is a pro-apoptotic factor in MCF-7 cells whereas in MDA-MB-231 cells it plays a pro-survival role. This conclusion is supported by the results obtained from the experiments assessing MOMP demonstrating that silencing of PDIAl reduced the polarization of the mitochondrial membrane in untreated MCF-7 cells and did not affect mitochondrial membrane disruption in the MDA-MB-231 cells under the same conditions. A potential mechanism justifying the differential effects of PDIAI silencing on mitochondrial membrane potential in the two cell lines is the mitochondrial colocalization of the PDIA1 (13) with the estrogen receptors ER $\alpha$ and ER $\beta$ in the MCF-7 breast cancer cells (62). Mitochondrial localization of ER $\alpha$ is associated with the modulation of the mitochondrial membrane potential and the inhibition of mitochondrial ROS generation due to the upregulation of the manganese superoxide dismutase activity in MCF-7 ER $\alpha$-positive cells (62).

The observed changes in the ROS generation, regulation of antioxidant cellular levels and mitochondrial membrane potential in the presence vs. the absence of PDIAI are indications that PDIA1 plays a critical role in the communication between endoplasmic reticulum and mitochondria and as such in the regulation of mitochondrial biogenesis and potentially energy metabolism (63). Support to this hypothesis is lent by observations showing the relationship between calcium and energy metabolism and the link between PDIA1 and the regulation of calcium homeostasis (64). Measurement of ATP production indicated that MCF-7 cells produced higher ATP levels in the absence of PDIAl whereas MDA-MB-231 in the absence of PDIAl produced significantly lower ATP levels. The crosstalk between PDIA1, p53 and Nox4 in the regulation of the activity of the mitochondrial respiratory chain $(65,66)$ and thus ATP production may be the reason for the differential ATP levels observed in the MCF-7 and MDA-MB-231 cells.

The immune system recognizes and eliminates neoplastic cells by identifying tumor specific antigens presented to the immune system cells in complex with MHC class I molecules. The cellular redox state is a crucial factor contributing to the efficient recognition of tumor antigens by the immune system (25) and PDIA1 governs the antigen processing and presentation events (22). Apart from its role in the stabilization of the early MHC class I complex and selection of the appropriate antigen PDIA1 has also been shown to participate in the regulation of the expression of the MHC class I (46). The expression of the classical or non-classical type of MHC class I is a critical point distinguishing the visible from the invisible to the immune system tumors, as overexpression of $H L A-G$ facilitates evasion of the immune surveillance by the tumor cells $(50,67)$. HLA-G has been shown to inactivate the effector function of the natural killer (NK) cells by associating with the inhibitory receptor of these cells (51). Results shown in Fig. 6 indicate that the HLA-G cell surface levels in the cells expressing PDIAI are higher compared to those in cells in which the expression of PDIAI had been silenced implying that by regulating the HLA-G surface levels PDIA1 potentially facilitates tumor cells to escape NK cell mediated innate immune responses thereby promoting immunotolerance (52).

PDIAl overexpression has been reported in several types of cancer and is correlated with metastasis and resistance to cancer therapy $(68,69)$. PDIA1 has also been shown to associate with well-characterized metastatic factors including metalloproteases, selectins and integrins $(68,70)$. Results shown in this study indicating correlation between the PDIA1/HLA-G mRNA ratio and overall survival in breast cancer patients provides further support for the hypothesis that PDIA1 is involved in the co-ordination of immune responses to tumor cells as well as in metastasis. Furthermore, the fact that high PDIAl and low HLA-G mRNA ratio was found in the subgroup of the stage $2 \mathrm{ER} \alpha$-positive breast cancer patients exhibiting low PDIA1 and high HLA-G mRNA levels the longer they survive, whereas low PDIAl and high HLA-G mRNA ratio was measured in the longer survivors of the same subgroup of $E R \alpha$-negative breast cancer patients could provide the potential means for selective treatment of the two different types of patients.

PDIA1 plays differential role in the regulation of the cellular redox state in the ER $\alpha$-positive MCF-7 vs. the TNBC MDA-MB-231 cells. In particular, silencing of PDIAI downregulated ROS levels in MCF-7 cells and upregulated ROS levels in MDA-MB-231 cells. Upregulation of GSH levels in PDIA1 silenced MCF-7 cells and downregulation of GSH levels in PDIA1 silenced MDA-MB-231 cells suggesting that PDIA1 is a pro-apoptotic factor in the former and pro-survival in the latter cells. ATP production was not affected in MCF-7 cells whereas MDA-MB-231 cells in which PDIA1 had been silenced produced lower ATP levels compared to PDIA1 expressing cells. The positive correlation of PDIAI mRNA levels with $H L A-G$ gene expression in breast cancer patients together with results showing downregulation of HLA-G levels on the extracellular membrane of MCF-7 and MDA-MB-231 cells lacking PDIA1 suggest that PDIA1 may contribute to the evasion of the immune surveillance by breast cancer cells. In addition the correlation of the ratio of PDIAI and HLA-G mRNA levels in stage 2 breast cancer patients indicates that PDIA1 could be used as a determining factor in the stratification of patients that would be responsive to immunotherapy.

\section{Acknowledgements}

Part of this study was included in R. Alhammad's PhD thesis. We would like to thank Gruppo Italiano Mesotelioma for support.

\section{Funding}

The study received funding from the Staff Development Fund, Naresuan University, Thailand Research Fund-Royal Golden Jubilee Ph.D. Program of Thailand and the British Council Newton Fund, the Center of Excellence on Medical Biotechnology (CEMB) (grant no.CEMB-RP-005), the Thailand Research Fund International Research Network (TRF-IRN) 
(grant no. IRN58W001), and the Siriraj Research Fund (grant no. R016034008), and the Siriraj Chalermphrakiat Grant.

\section{Availability of data and materials}

All data generated or analysed during this study are included in this published article

\section{Authors' contributions}

RA planned and performed experiments, analysed the results and prepared the draft of the manuscript, SK and NT performed experiments, analysed the results and reviewed the manuscript. TL, PY and LM analysed the results and reviewed the manuscript. MKD and CD have formed the hypothesis and supervised the research carried out, interpreted the results and prepared the manuscript. All authors approved the final manuscript.

\section{Ethical approval and consent to participate}

Not applicable.

\section{Patient consent for publication}

Not applicable.

\section{Competing interests}

The authors declare that they have no competing interests.

\section{References}

1. Liou GY and Storz P: Reactive oxygen species in cancer. Free Radic Res 44: 479-496, 2010.

2. Schieber M and Chandel NS: ROS function in redox signaling and oxidative stress. Curr Biol 24: R453-R462, 2014.

3. Eletto D, Chevet E, Argon Y and Appenzeller-Herzog C: Redox controls UPR to control redox. J Cell Sc 127: 3649-3658, 2014.

4. Almanza A, Carlesso A, Chintha C, Creedican S, Doultsinos D, Leuzzi B, Luis A, McCarthy N, Montibeller L, More S, et al: Endoplasmic reticulum stress signalling-from basic mechanisms to clinical applications. FEBS J 286: 241-278, 2019.

5. Oakes SA: Endoplasmic reticulum proteostasis: A key checkpoint in cancer. Am J Physiol Cell Physiol 312: C93-C102, 2017.

6. Zhang Z, Zhang L, Zhou L, Lei Y, Zhang Y and Huang C: Redox signaling and unfolded protein response coordinate cell fate decisions under ER stress. Redox Biol 25: 101047, 2018

7. Kranz P, Neumann F, Wolf A, Classen F, Pompsch M, Ocklenburg T, Baumann J, Janke K, Baumann M, Goepelt K, et al PDI is an essential redox-sensitive activator of PERK during the unfolded protein response (UPR). Cell Death Dis 8: e2986, 2017.

8. Okada K, Fukui M and Zhu BT: Protein disulfide isomerase mediates glutathione depletion-induced cytotoxicity. Biochem Biophys Res Commun 477: 495-502, 2016.

9. Grek C and Townsend DM: Protein disulfide isomerase superfamily in disease and the regulation of apoptosis. Endoplasmic Reticulum Stress Dis 1: 4-17, 2014.

10. Ali Khan $\mathrm{H}$ and Mutus B: Protein disulfide isomerase a multifunctional protein with multiple physiological roles. Front Chem 2: 70, 2014.

11. Wang C, Li W, Ren J, Fang J, Ke H, Gong W, Feng W and Wang CC: Structural insights into the redox-regulated dynamic conformations of human protein disulfide isomerase. Antioxid Redox Signal 19: 36-45, 2013.

12. Yu J, Li T, Liu Y, Wang X, Zhang J, Shi G, Lou J, Wang L, Wang CC and Wang L: Phosphorylation switches protein disulfide isomerase activity to maintain proteostasis and attenuate ER stress. EMBO J 39: e103841, 2020.
13. Turano C, Coppari S, Altieri F and Ferraro A: Proteins of the PDI family: Unpredicted non-ER locations and functions. J Cell Physiol 193: 154-163, 2002.

14. Parakh S and Atkin JD: Novel roles for protein disulphide isomerase in disease states: A double edged sword? Front Cell Dev Biol 3: 30, 2015.

15. Zhao G, $\mathrm{Lu} \mathrm{H}$ and $\mathrm{Li} \mathrm{C}$ : Proapoptotic activities of protein disulfide isomerase (PDI) and PDIA3 protein, a role of the Bcl-2 protein Bak. J Biol Chem 290: 8949-8963, 2015.

16. Ghanbari Movahed Z, Rastegari-Pouyani M, Mohammadi MH and Mansouri K: Cancer cells change their glucose metabolism to overcome increased ROS: One step from cancer cell to cancer stem cell? Biomed Pharmacother 112: 108690, 2019.

17. Higuchi T, Watanabe Y and Waga I: Protein disulfide isomerase suppresses the transcriptional activity of NF-kappaB. Biochem Biophys Res Commun 318: 46-52, 2004.

18. Goplen D, Wang J, Enger PO, Tysnes BB, Terzis AJ, Laerum OD and Bjerkvig R: Protein disulfide isomerase expression is related to the invasive properties of malignant glioma. Cancer Res 66: 9895-9902, 2006.

19. Reverendo M, Mendes A, Arguello RJ, Gatti E and Pierre P: At the crossway of ER-stress and proinflammatory responses. FEBS J 286: 297-310, 2019.

20. Obacz J, Avril T, Rubio-Patino C, Bossowski JP, Igbaria A, Ricci JE and Chevet E: Regulation of tumor-stroma interactions by the unfolded protein response. FEBS J 286: 279-296, 2019.

21. Lamers M, Berlin I and Neefjes J: Antigen presentation: Visualizing the MHC Class I peptide-loading bottleneck. Curr Biol 28: R83-R86, 2018.

22. Kang K, Park B, Oh C, Cho K and Ahn K: A role for protein disulfide isomerase in the early folding and assembly of MHC class I molecules. Antioxid Redox Signal 11: 2553-2561, 2009.

23. Park B, Lee S, Kim E, Cho K, Riddell SR, Cho S and Ahn K: Redox regulation facilitates optimal peptide selection by MHC class I during antigen processing. Cell 127: 369-382, 2006.

24. Cho K, Cho S, Lee SO, Oh C, Kang K, Ryoo J, Lee S, Kang S and Ahn K: Redox-regulated peptide transfer from the transporter associated with antigen processing to major histocompatibility complex class I molecules by protein disulfide isomerase. Antioxid Redox Signal 15: 621-633, 2011.

25. Lee S, Park B, Kang K and Ahn K: Redox-regulated export of the major histocompatibility complex class I-peptide complexes from the endoplasmic reticulum. Mol Biol Cell 20: 3285-3294, 2009.

26. Cerami E, Gao J, Dogrusoz U, Gross BE, Sumer SO, Aksoy BA, Jacobsen A, Byrne CJ, Heuer ML, Larsson E, et al: The cBio cancer genomics portal: An open platform for exploring multidimensional cancer genomics data. Cancer Discov 2: 401-404, 2012.

27. Soares Moretti AI and Martins Laurindo FR: Protein disulfide isomerases: Redox connections in and out of the endoplasmic reticulum. Arch Biochem Biophys 617: 106-119, 2017.

28. Guazzelli A, Meysami P, Bakker E, Demonacos C, Giordano A, Krstic-Demonacos M and Mutti L: BAP1 status determines the sensitivity of malignant mesothelioma cells to gemcitabine treatment. Int J Mol Sci 20: 429, 2019.

29. Forkink M, Smeitink JA, Brock R, Willems PH and Koopman WJ: Detection and manipulation of mitochondrial reactive oxygen species in mammalian cells. Biochim Biophys Acta 1797: 1034-1044, 2010.

30. Cereda M, Gambardella G, Benedetti L, Iannelli F, Patel D, Basso G, Guerra RF, Mourikis TP, Puccio I, Sinha S, et al: Patients with genetically heterogeneous synchronous colorectal cancer carry rare damaging germline mutations in immune-related genes. Nat Commun 7: 12072, 2016.

31. Barrey E, Saint-Auret G, Bonnamy B, Damas D, Boyer O and Gidrol X: Pre-microRNA and mature microRNA in human mitochondria. PLoS One 6: e20220, 2011.

32. Zibara K, Zeidan A, Bjeije H, Kassem N, Badran B and El-Zein N: ROS mediates interferon gamma induced phosphorylation of Src, through the Raf/ERK pathway, in MCF-7 human breast cancer cell line. J Cell Commun Signal 11: 57-67, 2017.

33. Oh SY, Sohn YW, Park JW, Park HJ, Jeon HM, Kim TK, Lee JS, Jung JE, Jin X, Chung YG, et al: Selective cell death of oncogenic Akt-transduced brain cancer cells by etoposide through reactive oxygen species mediated damage. Mol Cancer Ther 6: 2178-2187, 2007.

34. Hodny Z, Reinis M, Hubackova S, Vasicova P and Bartek J: Interferon gamma/NADPH oxidase defense system in immunity and cancer. Oncoimmunology 5: e1080416, 2016. 
35. Laurindo FR, Pescatore LA and Fernandes Dde C: Protein disulfide isomerase in redox cell signaling and homeostasis. Free Radic Biol Med 52: 1954-1969, 2012.

36. Hegedús C, Kovács K, Polgár Z, Regdon Z, Szabó É, Robaszkiewicz A, Forman HJ, Martner A and Virág L: Redox control of cancer cell destruction. Redox Biol 16: 59-74, 2018.

37. Traverso N, Ricciarelli R, Nitti M, Marengo B, Furfaro AL, Pronzato MA, Marinari UM and Domenicotti C: Role of glutathione in cancer progression and chemoresistance. Oxid Med Cell Longev 2013: 972913, 2013.

38. Bulleid NJ: Disulfide bond formation in the mammalian endoplasmic reticulum. Cold Spring Harb Perspect Biol 4: a013219, 2012.

39. Herrera-Cruz MS and Simmen T: Cancer: Untethering mitochondria from the endoplasmic reticulum? Front Oncol 7: 105, 2017.

40. Koczian F, Naglo O, Vomacka J, Vick B, Servatius P, Zisis T, Hettich B, Kazmaier U, Sieber SA, Jeremias I, et al: Targeting the endoplasmic reticulum-mitochondria interface sensitizes leukemia cells to cytostatics. Haematologica 104: 546-555, 2019.

41. Marchi S, Patergnani S and Pinton P: The endoplasmic reticulum-mitochondria connection: One touch, multiple functions. Biochim Biophys Acta 1837: 461-469, 2014.

42. Kerkhofs M, Bittremieux M, Morciano G, Giorgi C, Pinton P, Parys JB and Bultynck G: Emerging molecular mechanisms in chemotherapy: $\mathrm{Ca}(2+)$ signaling at the mitochondria-associated endoplasmic reticulum membranes. Cell Death Dis 9: 334 , 2018.

43. Yoboue ED, Sitia R and Simmen T: Redox crosstalk at endoplasmic reticulum (ER) membrane contact sites (MCS) uses toxic waste to deliver messages. Cell Death Dis 9: 331 , 2018.

44. Wacquier B, Combettes L and Dupont G: Cytoplasmic and mitochondrial calcium signaling: A two-way relationship. Cold Spring Harb Perspect Biol 11: a035139, 2019.

45. So JS: Roles of endoplasmic reticulum stress in immune responses. Mol Cells 41: 705-716, 2018.

46. Kukita K, Tamura Y, Tanaka T, Kajiwara T, Kutomi G, Saito K, Okuya K, Takaya A, Kanaseki T, Tsukahara T, et al: Cancer-associated oxidase ERO1- $\alpha$ regulates the expression of MHC class I molecule via oxidative folding. J Immunol 194 4988-4996, 2015.

47. Kim Y, Kang K, Kim I, Lee YJ, Oh C, Ryoo J, Jeong E and Ahn K: Molecular mechanisms of MHC class I-antigen processing: Redox considerations. Antioxid Redox Signal 11: 907-936, 2009.

48. Binder RJ: Functions of heat shock proteins in pathways of the innate and adaptive immune system. J Immunol 193: 5765-5771, 2014.

49. Allen RL: Non-classical immunology. Genome Biol 2: REPORTS4004, 2001.

50. da Silva GB, Silva TG, Duarte RA, Neto NL, Carrara HH, Donadi EA, Goncalves MA, Soares EG and Soares CP: Expression of the classical and nonclassical HLA molecules in breast cancer. Int J Breast Cancer 2013: 250435, 2013.

51. Sivori S, Vacca P, Del Zotto G, Munari E, Mingari MC and Moretta L: Human NK cells: Surface receptors, inhibitory checkpoints, and translational applications. Cell Mol Immunol 16: 430-441, 2019.

52. Morandi F, Rizzo R, Fainardi E, Rouas-Freiss N and Pistoia V: Recent advances in our understanding of HLA-G biology: Lessons from a wide spectrum of human diseases. J Immunol Res 2016: 4326495, 2016.
53. Niu XL, Wang Y, Yao Z, Duan H, Li Z, Liu W, Zhang H and Deng WM: Autocrine interferon-gamma may affect malignant behavior and sensitivity to tamoxifen of MCF-7 via estrogen receptor $\beta$ subtype. Oncol Rep 34: 3120-3130, 2015.

54. Schultz-Norton JR, McDonald WH, Yates JR and Nardulli AM: Protein disulfide isomerase serves as a molecular chaperone to maintain estrogen receptor alpha structure and function. Mol Endocrinol 20: 1982-1995, 2006.

55. Hashimoto S and Imaoka S: Protein-disulfide isomerase regulates the thyroid hormone receptor-mediated gene expression via redox factor-1 through thiol reduction-oxidation. J Biol Chem 288: 1706-1716, 2013.

56. Mancini A, Bruno C, Vergani E, Guidi F, Angelini F, Meucci E and Silvestrini A: Evaluation of oxidative stress effects on different macromolecules in adult growth hormone deficiency. PLoS One 15: e0236357, 2020.

57. Boudreau HE, Casterline BW, Burke DJ and Leto TL: Wild-type and mutant p53 differentially regulate NADPH oxidase 4 in TGF- $\beta$-mediated migration of human lung and breast epithelial cells. Br J Cancer 110: 2569-2582, 2014.

58. Trevelin SC and Lopes LR: Protein disulfide isomerase and Nox: New partners in redox signaling. Curr Pharm Des 21: 5951-5963, 2015.

59. Lappi AK and Ruddock LW: Reexamination of the role of interplay between glutathione and protein disulfide isomerase. J Mol Biol 409: 238-249, 2011

60. Hudson DA, Gannon SA and Thorpe C: Oxidative protein folding: From thiol-disulfide exchange reactions to the redox poise of the endoplasmic reticulum. Free Radic Biol Med 80: 171-182, 2015.

61. Coppola S and Ghibelli L: GSH extrusion and and the mitochondrial pathway of apoptotic signalling. Biochem Soc Trans 28: 56-61,2000.

62. Pedram A, Razandi M, Wallace DC and Levin ER: Functional estrogen receptors in the mitochondria of breast cancer cells. Mol Biol Cell 17: 2125-2137, 2006.

63. Fan Y and Simmen T: Mechanistic connections between endoplasmic reticulum (ER) redox control and mitochondrial metabolism. Cells 8: 1071, 2019.

64. Gutierrez T and Simmen T: Endoplasmic reticulum chaperones tweak the mitochondrial calcium rheostat to control metabolism and cell death. Cell Calcium 70: 64-75, 2018.

65. Dikalov S: Cross talk between mitochondria and NADPH oxidases. Free Radic Biol Med 51: 1289-1301, 2011.

66. Kozieł R, Pircher H, Kratochwil M, Lener B, Hermann M, Dencher NA and Jansen-Dürr P: Mitochondrial respiratory chain complex I is inactivated by NADPH oxidase Nox4. Biochem J 452: 231-239, 2013

67. Kochan G, Escors D, Breckpot K and Guerrero-Setas D: Role of non-classical MHC class I molecules in cancer immunosuppression. Oncoimmunology 2: e26491, 2013.

68. Xu S, Sankar S and Neamati N: Protein disulfide isomerase: A promising target for cancer therapy. Drug Discov Today 19: 222-240, 2014

69. Lee $\mathrm{E}$ and Lee DH: Emerging roles of protein disulfide isomerase in cancer. BMB Rep 50: 401-410, 2017.

70. Rosenberg N, Mor-Cohen R, Sheptovitsky VH, Romanenco O, Hess $\mathrm{O}$ and Lahav J: Integrin-mediated cell adhesion requires extracellular disulfide exchange regulated by protein disulfide isomerase. Exp Cell Res 381: 77-85, 2019.

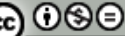

This work is licensed under a Creative Commons Attribution-NonCommercial-NoDerivatives 4.0 International (CC BY-NC-ND 4.0) License. 